\title{
Preconceptual Design for the Electrostatic Enclosure
}

\author{
L. C. Meyer
}

Published September 1992

\section{Idaho National Engineering Laboratory EG\&G Idaho, Inc. Idaho Falls, Idaho 83415}

\author{
Prepared for the
}

U.S. Department of Energy

Offlce of Environmental Restoration and Waste Management

Under DOE Idaho Fleld Office

Contract DE-AC07-76ID01570

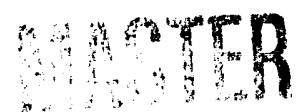


Preconceptual Design Report for the Electrostatic Enclosure

EGG-WTD-10450

Approved by:
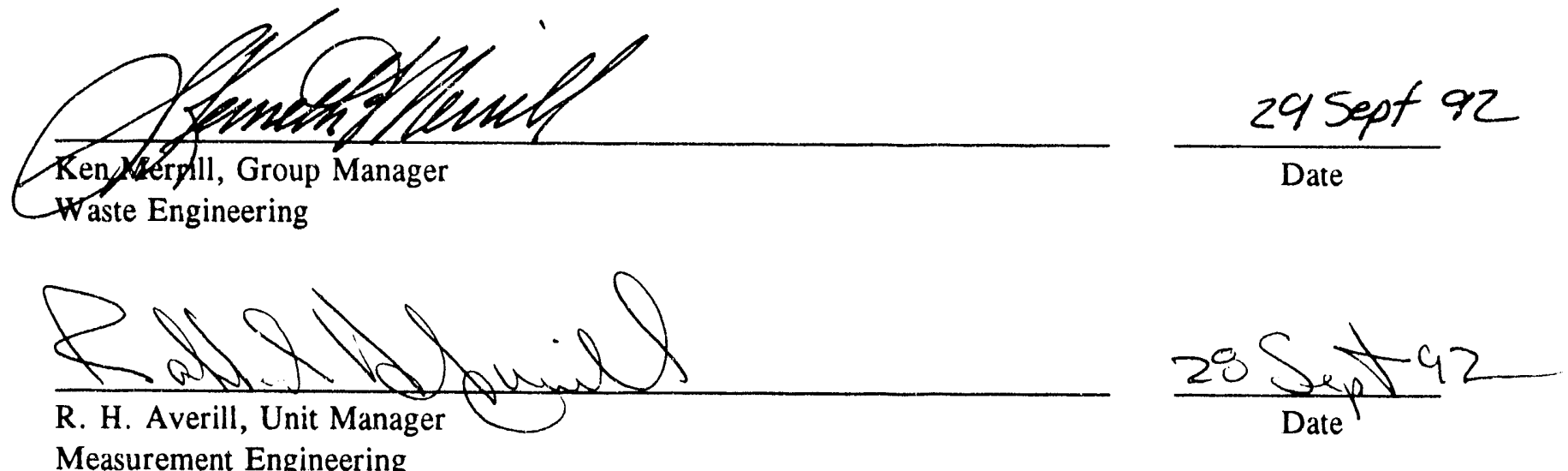

Measurement Engineering

Reviewed by:

Lither Bhelisotin

L. Dale Watson, Principal Project Engineer Measurement Engineering

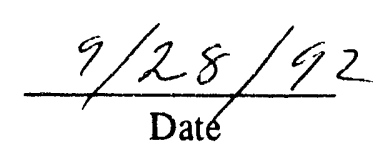

ii 


\section{ABSTRACT}

This report presents a preconceptual design (design criteria and assumptions) for electrostatic enclosures to be used during buried transuranic waste recovery operations. These electrostatic enclosures (along with the application of dust control products) will provide an in-depth contamination control strategy. As part of this preconceptual design, options for electrostatic curtain design are given including both hardwall and fabric enclosures. Ventilation systems, doors, air locks, electrostatic curtains, and supporting systems also are discussed. In addition to the conceptual design, engineering scale tests are proposed to be run at the Test Reactor Area. The planned engineering scale tests will give fnal material specifications for full-scale retrieval demonstrations. 


\section{SUMMARY}

This report presents the preconceptual design (design criteria and assumptions) of a moveable electrostatic enclosure that can be used during transuranic waste recovery operations. Electrostatic curtain technology is being evaluated as an added contamination control technique for use during handling of transuranic material that might be encountered in the retrieval of buried waste. The transuranic contaminants include small (micrometer to submicrometer) particles of plutonium and americium compounds associated with defense-related waste. Remediation concepts for the recovery and treatment of the buried waste sites have been developed by the Buried Waste Integrated Demonstration Program for the U.S. Department of Energy complex waste sites.

Based on design criteria, two types of enclosures have been identified: a Kelly system stainless steel enclosure and a conductive fabric wall enclosure from Califomia Industrial Resources, Inc. These enclosures are representative of the solid and fabric wall enclosures available from industry.

The solid wall portable units are avai'able in clearspan widths from 18 to $48 \mathrm{ft}$ and nominal eave heights from 10 to $22 \mathrm{ft}$. Each panel comes assembled on a steel frame and the frames clip together using a locking key system. A variety of materials are used for inserts and sheeting. Any panel in an enclosure can be an access point. Sheeting can be put on the outside, inside, or both with or without insulation. If used as an outside enclosure, the sheeting could be metal with an overlapping edge to create a watertight seal. Inside sheeting could be a smooth stainless steel for easy decontamination. Wall and roof panels are identical and can be interchanged. Doors, windows, or feedthrough panels can be inserted where desired by replacing a standard panel. Since this is a metal enclosure, it can be grounded easily.

Fabric enclosures have fabric material on a steel or aluminum frame. The fabric can be on the inside or outside of the frame. The fabric may be electrically conductive so it can be grounded to minimize contamination spread or collection. Vehicular doors or personnel doors of various types can be installed in the ends of the enclosure. The enclosure can be extended to any length by adding sections. The enclosures can be sealed along the foundations and doors to maintain a negative pressure inside. The fabric has a Class 1 fire resistance rating and when used outdoors has an 8- to 10-year life expectancy. The manufacturer claims that their enclosures have been used extensively for storage and containment of hazardous materials such as benzene, asbestos, and radioactive soils at various government facilities. An alternative to the inner enclosure is to have only a divider wall across the outer building. The walls and ceiling of the outer building would be part of the containment a'ea and the divider placed across the building would separate the dig area from the clean area. This option requires decontamination of the walls and ceiling of the outer building when the waste recovery job is completed. The arrangement would allow the outer building lighting system, bridge crane, fire system, conveyor system, and robotic systems to operate normally within the enclosure dig area. Depending on the type of outer building selected, the divider could be hardwall panels or fabric. Air locks, doors, or clear panels for windows could be placed where desired in the divider. Another concept was to make the divider curtain in two parts and have only the excavator boom in the dig area. The upper part would be solid material and the lower would be a sliding door with an accordion fold electrostatic material on each side. The sliding door would have an elastic web attached to the boom that would act as the air intake into the dig area. Since clean air would be passing through the web from the clean area, the main part of the excavator would be kept clean. The elastic web would allow the excavator boom to move freely up, down, left, or right when the excavator stays in one position. When the excavator moves to a new location along the dig face, it would pull the sliding door and the accordion fold curtain along with it to the new location.

The ventilation system for the electrostatic enclosure will maintain a negative pressure in the excavation area. The air intake will be located just above the dig area and the air output will be through the stack at the rear of the outer building. An electrostatic device to remove charged particles and larger aerosol particles from the exhaust air will be located just before the high- 
efficiency particulate air filter. Periodically, a collection box located under the electrostatic device will be changed and the contents added to the waste treatment stream.

Engineering scale tests are recommended to provide needed background information on both hardwall and fabric structures before final design of electrostatic enclosures. Methods of monitoring plutonium in the electrostatic enclosure will be part of the test plan and include using an aerosol sampler and coupons. The results of these tests should determine if the electrostatic concepts are suitable for large-scale applications such as waste recovery operations. 


\section{CONTENTS}

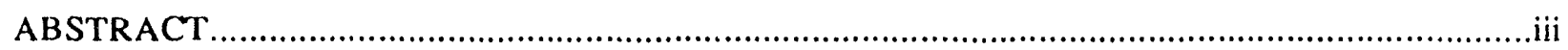

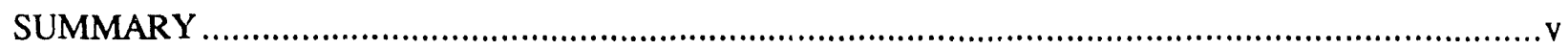

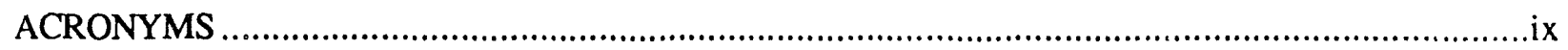

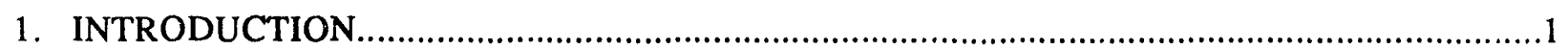

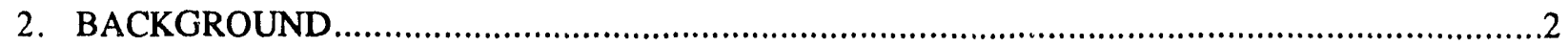

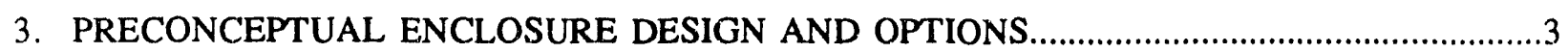

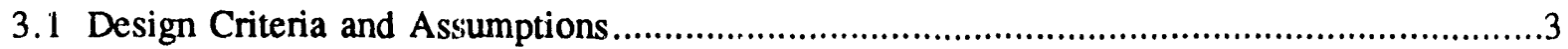

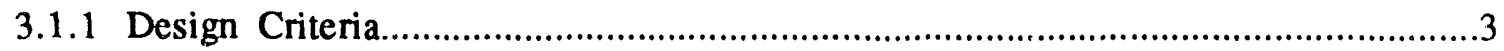

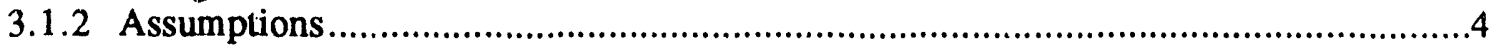

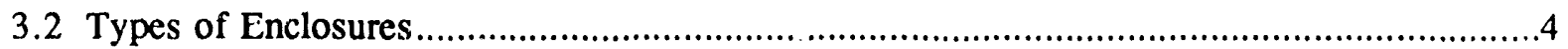

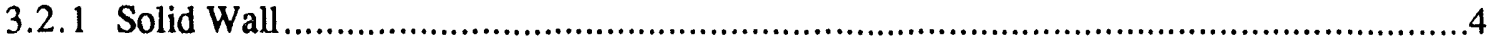

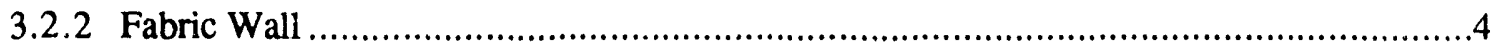

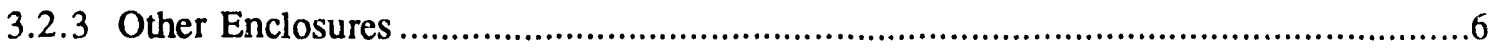

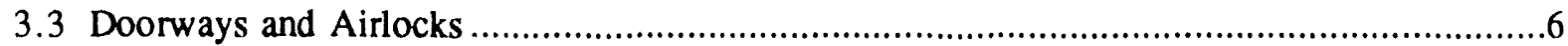

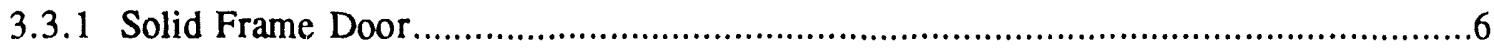

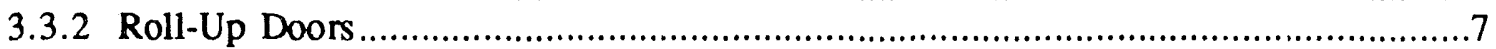

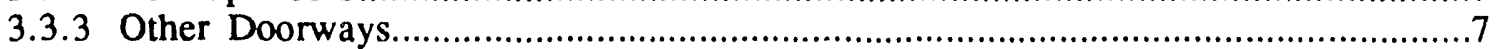

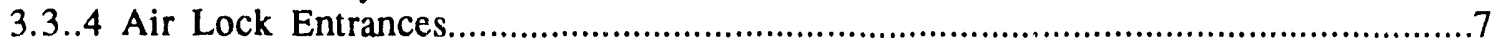

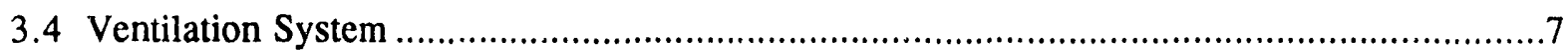

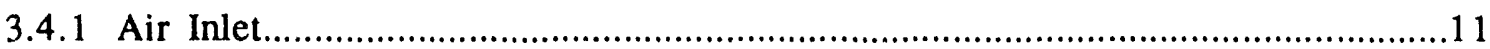

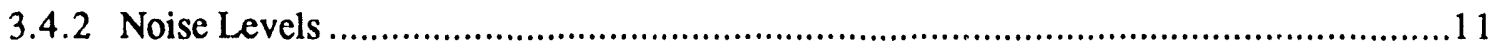

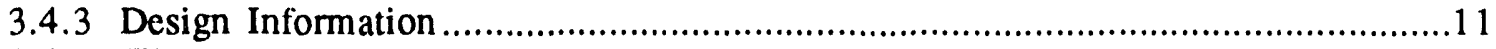

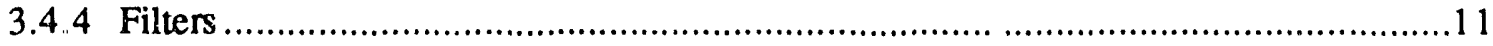

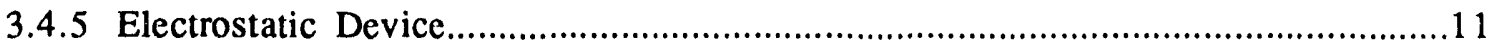

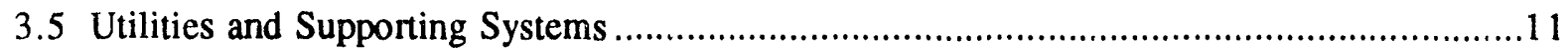

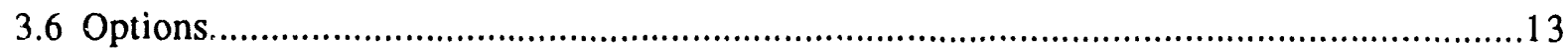

3.6.1 Electrostatic Curtain Dividers........................................................................ 13

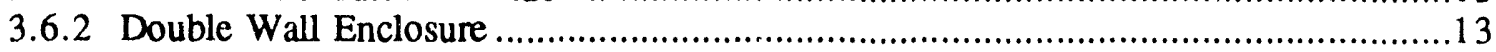

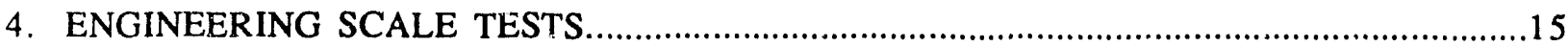

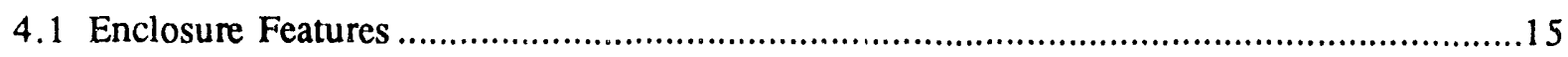

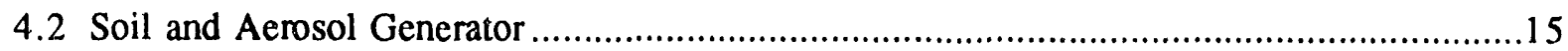

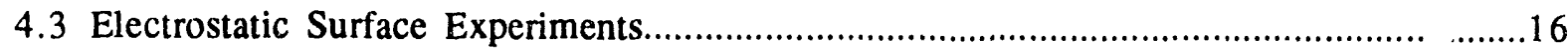




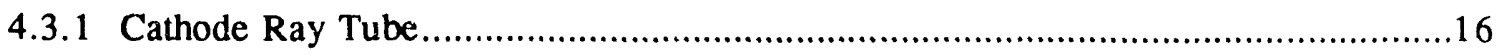

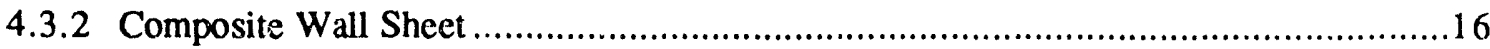

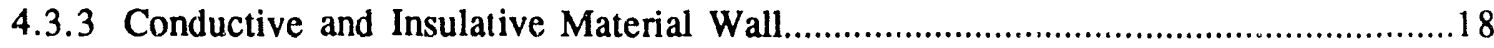

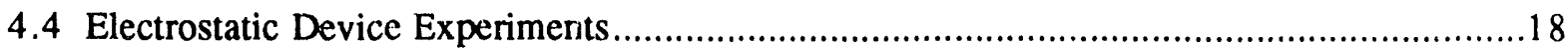

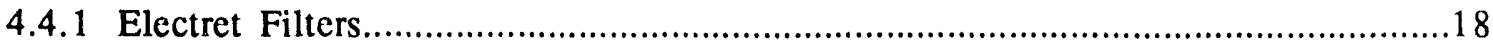

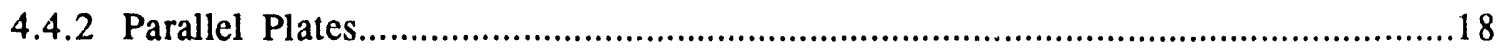

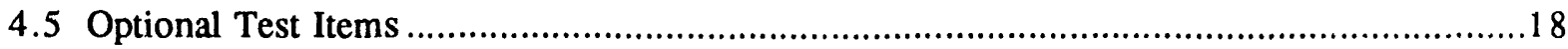

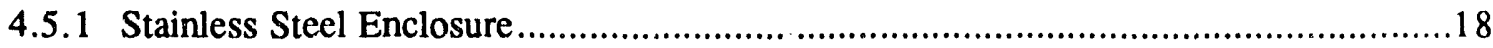

4.5.2 Comparison of Hardwall and Fabric Enclosures ...............................................18

4.5.3 Alternate Methods of Obtaining Samples.............................................................19

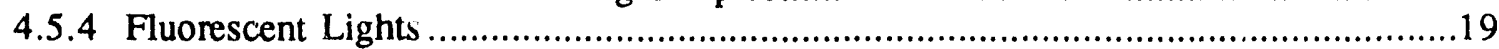

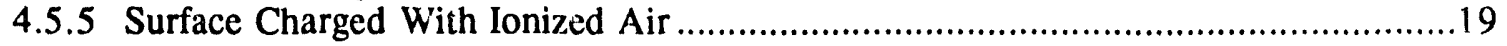

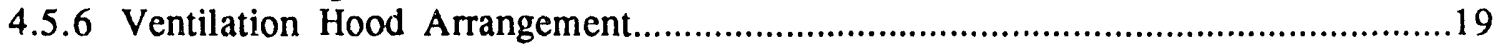

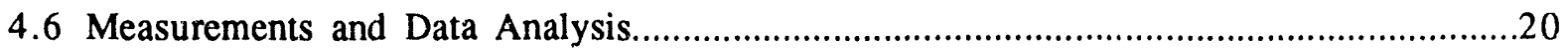

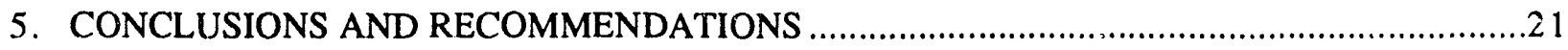

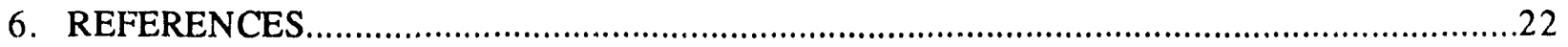

\section{FIGURES}

1. Conceptual layout of the cold waste pit outer building and ES enclosure ..............................

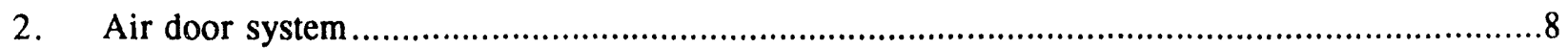

3. ES doorway with positive charge on frame

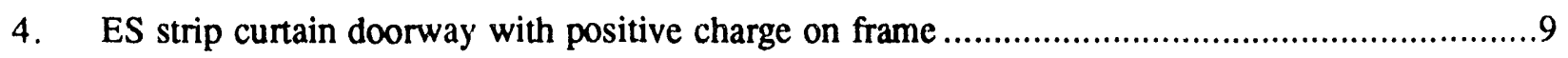

5. Vehicle and personnel air lock entrances for the ES enclosure ........................................10

6. Dual set of ES plates and collection box in ventilation duct................................................12

7. ES curtain divider with excavator penetration into the dig area.............................................14

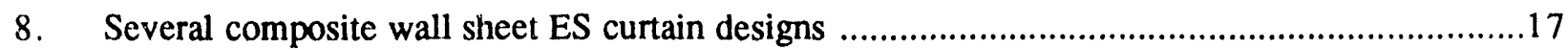




\section{ACRONYMS}

ASTM American Society for Testing and Materials

CRT cathode ray tube

CWS composite wall sheet

DOE U.S. Department of Energy

ES electrostatic

FY fiscal year

HEPA high-efficiency particulate filter

INEL Idaho National Engineering Laboratory

SMACNA Sheet Metal and Air Conditioning Contractors National Association 


\section{Conceptual Design Report for an Electrostatic Enclosure}

\section{INTRODUCTION}

The Idaho National Engineering Laboratory (INEL) is evaluating electrostatic (ES) curtain technology as a contamination control technique to handle transuranic material during retrieval of buried waste. The transuranic contaminants include micrometer to submicrometer particles of plutonium and americium compounds associated with defense-related waste.

This report presents the preconceptual design of a moveable ES enclosure that ultimately might be used during radioactive waste recovery operations. The design includes a ventilation system with ES devices and filters venting to a stack, and doorways and air locks for personnel and equipment. Remediation concepts for the recovery and treatment of the buried waste have been developed by the Buried Waste Integrated Demonstration Program in conjunction with U.S. Department of Energy (DOE) needs to develop a long-term strategy for improving buried waste remediation capabilities throughout the DOE system. ${ }^{1}$ This report also presents details of enginecring scale tests to support further development of the ES curtain design concept before the full-scale ES enclosure demonstrations. 


\section{BACKGROUND}

The ES curtain research project was started in fiscal year (FY)-90 as a promising component of an overall contamination control scheme for retrieval of buried transuranic waste. ${ }^{2}$ ES curtains were examined as a possible means of cnllecting, repelling, or neutralizing charged plutonium and americium particles found in airborne dust generated during any future recovery operation of transuranic waste.

Since a negative surface will attract positively charged particles and a positive surface will repel these same particles, an ES device can control charged airborne particles passing within the range of the electric field. The charged particles can be attracted, repelled, or neutralized by using the appropriate surface conditions on the wall of the containment space. This will also be true for combined particles (plutonium attached to dust particles). If plutonium is attached to negatively charged dust particles and the resulting combined charge is negative, the combined particles will be attracted to a positive surface. A negative surface will attract positively charges particles. If the combined particles have a neutral charge, they will be unaffected by the electric field and will be collected by the electret filter [or high-efficiency particulate air (HEPA) filter] in the ventilation system outlet. The FY-90 and FY-91 ES curtain studies demonstrated that the minimum amount of dust and contamination are collected on a surface that is grounded (neutral charge). In those studies, plutonium was found on both positively and negatively charged surfaces, although more was found on the negatively charged surfaces.

Since ES charge un accumulate on materials that are insulators, such as polyethylene plastic, the charged materis $1 s$ contribute to the spread of airborne contamination. ES charge buildup can be eliminated by using a conducting material that drains off any accumulated charges. A grounded conducting surface rot only collects a minimum amount of dust and contamination but also may discharge any charged particles that strike the surface, are neutralized, and are then collected by the electret filter.

Electret filters with high efficiency for collecting submicrometer particles have been developed to clean air with less pressure drop than purely mechanical filters. Electret filters were included in the F . -91 ES curtain contamination control experiments and worked quite well. ${ }^{3}$

The obvious application of ES curtains is to establish enclosure walls that can attract, repel, or neutralize plutonium and americium contaminants. By having a grounded surface (electrically conductive), charged particles coming into contact with the surface would be discharged, with the minimum number becoming attached. Additionally, using ES devices in ventilation systems can promote the removal of charged airborne plutonium and americium particles from the system. 


\section{PRECONCEPTUAL ENCLOSURE DESIGN AND OPTIONS}

\subsection{Design Criteria and Assumptions}

\subsubsection{Design Criterla}

The conceptual enclosure design is based on the following design criteria and assumptions.

1. The ES enclosure will be made of conducting material so it can be grounded to minimize contamination spread from ES buildup.

2. The enclosure design will be modular. It can be extended by adding 20 foot lengths.

3. The framework for the enclosure will be on the outside with wall material on the inside. The frame will have lifting points so the enclosure can be moved intact by a crane.

4. The ES enclosure will be light enough to be moved with a crane. This assumes that a crane is available in the outer building to move the enclosure. The other alternatives are to attach wheels to the frame and move the enclosure on a portable track or pad, or to decontaminate the enclosure, disassemble it, and reassemble it at the new location.

5. The walls of the enclosure will be $20 \mathrm{ft}$ high on the sides and between 26 and $30 \mathrm{ft}$ high at the center.

6. The inside surface of the enclosure should be smooth for easy decontamination and cleaning.

7. The enclosure will be capable of maintaining a negative pressure of 0.05 psi with the ventilation system. The outer building will not be maintained at a negative $0.05 \mathrm{psi}$ pressure.

8. Intake air filters will be provided around doorways and air locks.

9. Personnel, vehicles, and waste containers entering or exiting the enclosure will do so through air locks. Self sealing doorways will be used on each side of the air lock.

10. The enclosure materials will be fire resistant.

11. Any lifting and moving system needed to support the recovery operations spray system, fixing systems, and coupon recovery will be a portable system and will be capable of operating within the ES enclosure.

12. Air locks will be provided as part of the conveyor system for moving waste containers in and out of the ES enclosure.

13. The cable feedthrough for the umbilical cord of the excavator, as well as any other cable feedthroughs needed to support the recovery operation, will be designed into the ES enclosure when the need and specifications for them become available. The feedthroughs are considered a part of other systems, and interface details will be jointly worked out with the equipment engineers.

14. The foundation for the ES enclosure will be portable bar and slab sections that will move with the enclosure. 
15. The grounding grid for the uuter building will handle the grounding requirements of the ES enclosure.

16. The enclosure sections or panels should be capable of being stored in a compact form when disassembled. If a section is made of fabric, it should be able to be disposed of as compactible waste at the end of its life.

\subsubsection{Assumptlons}

1. The cold waste pit is used as a representative potential first use of the ES enclosure demonstration (see Figure 1). The cold waste pit is located near the Radioactive Waste Management Complex at the INEL.

2. An outer building over the demonstration site will be provided.

3. The ES ericlosure will be $48 \mathrm{ft}$ wide and $40 \mathrm{ft}$ long. This allows maneuvering space for the digging activity and keeps the enclosed area at a minimum to control contamination and allow the enclosure to be moved easily.

\subsection{Types of Enclosures}

Two types of enclosures are considered for this application: a Kelly system stainless steel enclosure and a conductive fabric wall enclosure from California Industrial Resources, Inc. ${ }^{a}$ These enclosures are representative of solid and fabric wall enclosures available from industry. Two other enclosures also are discussed.

\subsubsection{Solld Wall}

Kelly Klosure Systems 2 units are described by the company as portable units. These units are available in clearspan widths of $18 \mathrm{ft}$ to $48 \mathrm{ft}$ and nominal eave heights of $10 \mathrm{ft}$ to $22 \mathrm{ft}$. Each panel comes assembled on a steel frame and the frames clip together using the Kelly locking key system. A variety of materials are used for inserts and sheeting. Sheeting can be put on the outside, inside, or both with or without insulation. If used as an outside enclosure, the sheeting could be metal with an overlapping edge to create a watertight seal, while an inside sheeting could be a smooth stainless steel for easy decontamination.

Any panel in the enclosure can be an access point. Wall and roof panels are identical and can be interchanged. Doors, windows, or feedthrough panels can be inserted where desired by replacing a standard panel. Because this is a metal enclosure, it can be grounded easily. A rule of thumb for determining the weight of steel enclosures is to use $2.2 \mathrm{lb} / \mathrm{ft}^{2}$. Therefore, an enclosure that is $48 \mathrm{ft} \times$ $40 \mathrm{ft}$ would weigh about $4,800 \mathrm{lb}$.

\subsubsection{Fabris, Wall}

Large Califoinia Industiial Resources enclosures use fabric material on a steel frame. The fabric can be on the inside or outside of the frame, and may be electrically conductive so it can be grounded to minimize contamination spread or collection. Vehicular doors or personnel doors of various types can be installed in the ends of the enclosure. The enclosure can be extended to any length by adding sections.

a. Mention of specific products or manufacturers in this document implies neither endorsement, preference, nor disapproval by the U.S. Government, any of its agencies, or EG\&G Idaho, Inc., of the use of a specific prexduct for any purpose. 


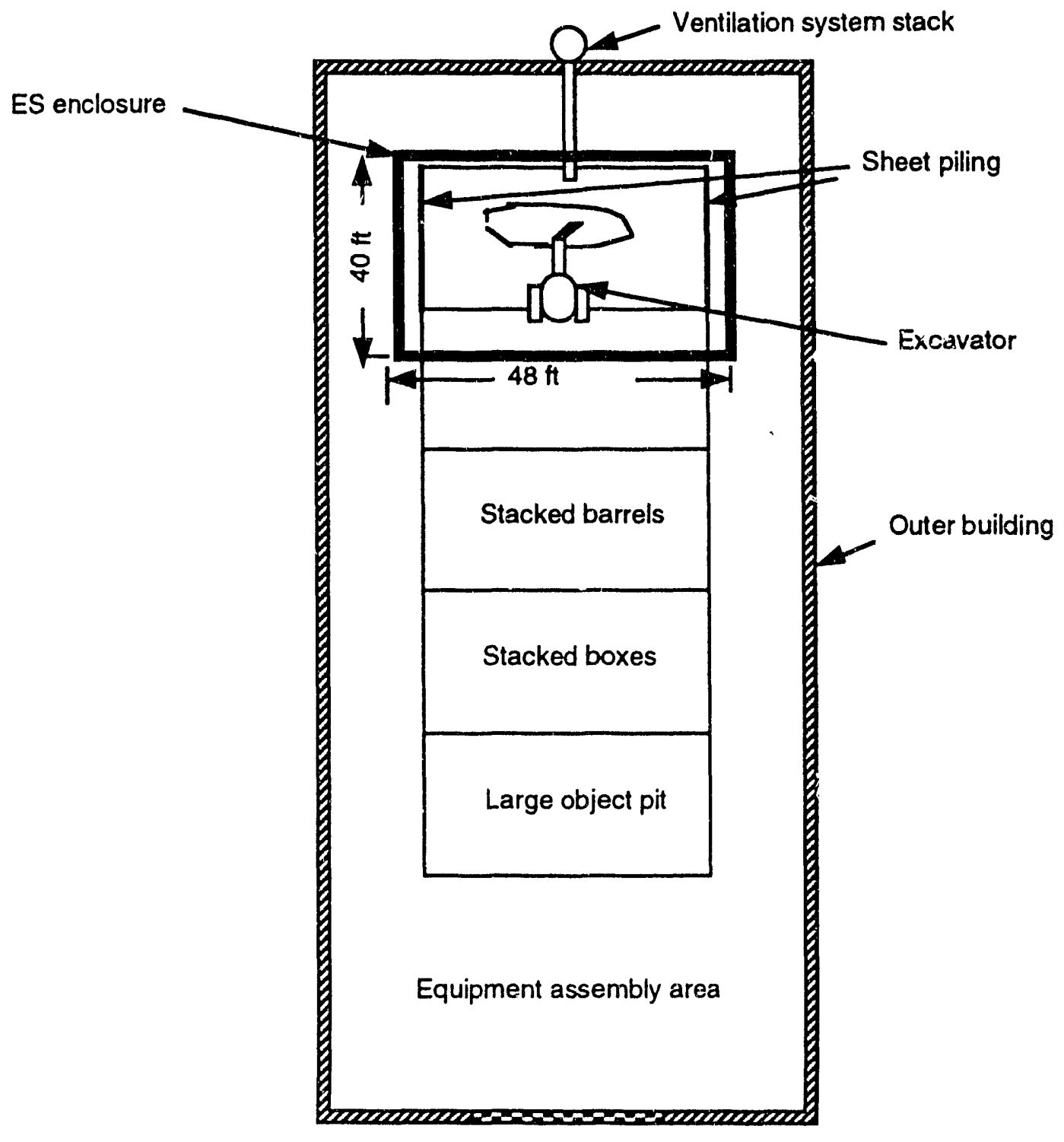

Roll up door

Figure 1. Conceptual layout of the cold waste pit outer building and ES enclosure. 
A negative pressure can be maintained inside by sealing the enclosure along the foundations and doors. The fabric has a Class 1 fire resistance rating and when used outdoors has an 8- to 10year life expectancy. The manufacturer claims that their enclosures have been usid extensively for storage and containment of hazardous materials such as benzene, asbestos, and radioactive soils at various government facilities.

The electrical resistivity specifications for this conductive fabric are

- American Society for Testing and Materials (ASTM) 0257 , surface resistivity face and back:

$10^{8}-10^{9} \mathrm{ohm} / \mathrm{sq}$

- ASTM 0257, volume resistivity:

$10^{9} \mathrm{ohm} / \mathrm{sq}$

- ASTM F150, resistivity face and back:

$500 \mathrm{~V}-10^{7} \mathrm{ohm}$

$100 \mathrm{~V}-10^{7} \mathrm{~g}:$

- EOS/ESD S-4 point, face and back:

$10^{7} \mathrm{ohm}$ at $10 \mathrm{~V}$ and $\mathrm{i} 2.5 \%$

relative humidity

- Static Decay Federal Test 4046.1:

$500 \mathrm{~V}$ to $0 \mathrm{~V}$ in 0.01 seconds at $12.5 \%$ relative humidity.

The cost for the conductive fabric is about $10-15 \%$ higher than their regular material. The fabric has one smooth side and weighs about $20 \mathrm{oz} / \mathrm{yd}^{2}$. A fabric enclosure on a steel frame would weigh about two-thirds of a steel structure.

\subsubsection{Other Enclosures}

3.2.3.1 Pressurized Fabrlc Wall. These enclosures have inner and outer walls of fabric with the space between the walls slightly pressurized. The pressurized structure would require an air compressor and periodic monitoring for leaks. This option was not pursued because the double wall probably is not needed for an inner enclosure. However, this might be a viable option for a standalone enclosure using the outer covering as a weather shield.

3.2.3.2 Balloon Wall. Balloon wall enclosures are constructed in tubular sections that are inflated and air supported. This option was not pursued because for large enclosures (40 to $60 \mathrm{ft}$ across) external suppost probably would be needed. The external support would make a balloon cnclosure similar 0 the fabric enclosure, but the balloon enclosure would require additional equipment for inflation and monitoring.

\subsection{Doorways and Air Locks}

Doorways will be either a solid frame door or a roll-up fabric door. Other doorways considered include air doors, open electrostatically charged doorways, and strip curtains. Personnel or vehicle air locks will have either a solid frame door or a roll-up door on each side of the air lock. The doors will be self sealing when closed.

\subsubsection{Solld Frame Door}

If a solid frame door is used, it will be a standard prehung door for personnel entrance or a large door similar to a garage door for vehicle entrance. 


\subsubsection{Roll-Up Doors}

A roll-up door will be either a metal or fabric door supplied by the enclosure inanufacturer that will roll up to the tip of the door. It could be either manually operated or run with remote control.

\subsubsection{Other Doorways}

3.3.3.1 Alr Door. An air door is a curtain of air that has an inlet at the top and draws air out at the bottom. The air return would have an electret filter to remove any radioactive particles. A small ramp would be placed on each side of the door to minimize dust carried $c$ ' air system by vehicle traffic. An air ionizer could be placed at the top of the dour along the air entrance grill to provide either a charged or neutral ion stream io help the air streain capture any airborne contamination particles. A conceptual sketch of an air door system is shown in Figure 2. The air door concept was dropped because it would no: have a positive contamination control wall. Also, air turbulence around the door might allow radioactive particles to escape the containment area.

3.3.3.2 Electrostatlc Door. In an ES door, the door frame would be charged positively with respect to ground and would have a thin insulating plastic cover to protect personnel from accidentally coming into contact with the charged metal frame. During the short period of time personnel are entering or leaving the enclosure, the voltage could be turned off and the frame grounded to eliminate any safety concern.

Figure 3 shows a conceptual ES doonvay. The ES doorway was not considered further because it would not be a positive contamination control wall-neutrally charged contaminated particles could pass through the opening and escape the control area.

3.3.3.3 Strip Curtaln. The strip curtain consists of a doorway or wall that has strips of material hanging in the opening and air flow through the curtain toward the ventilation system. The advantage of the strip curtain is that the excavator boom could reach through the strip curtain into the dig area while the rest of the excavator could stay outside. The idea behind this arrangement is that it would keep the excavator clean and require less maintenance. The strip curtain could be charged or uncharged with respect to ground and would be similar to the ES door (see Figure 4). The strip curtain was not considered because, like the ES door, it would not provide a positive control under all operating conditions.

\subsubsection{Alr Lock Entrances}

Air lock entrances will help maintain a negative air pressure in the ES enclosure and will minimize the chance of any contamination escaping. Air lock entrances for personnel as well as vehicles could be provided as shown in Figure 5 with air inlet filters located around each air lock entrance door. The air from these input filters would flow toward the intake of the dig area ventilation system, carrying any airborne particles with it and trapping them in the ES ventilation filters.

\subsection{Ventilation System}

The ventilation system for the ES enclosure will maintain a negative pressure in the excavation area. The air intake will be located just above the dig area and the air output will be through the stack at the rear of the outer building. An ES device to remove charged particles and larger aerosol particles from the exhaust air will be located just before the HEPA filter. The HEPA filter will not have to be changed as often with this arrangement. Periodically, a collection box located under the ES device will be changed and the contents added to the waste treatment stream. 


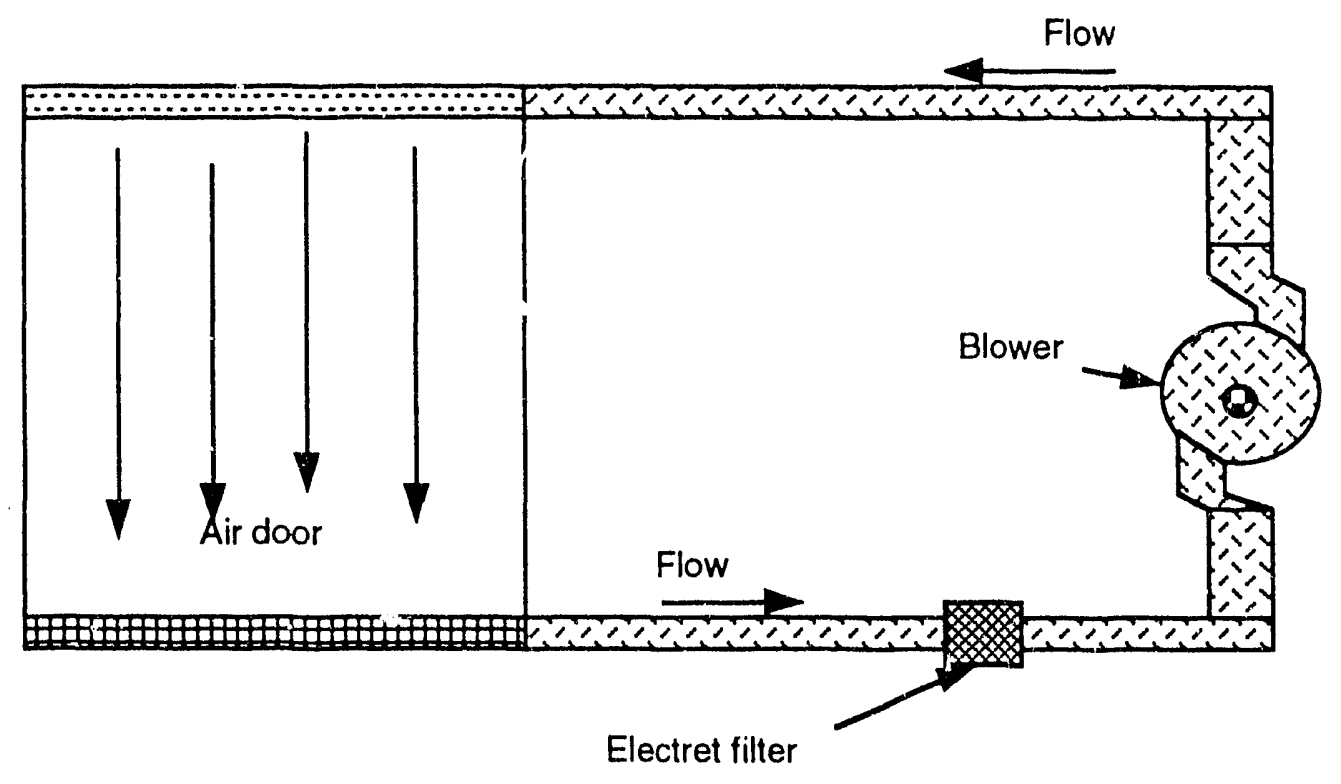

Figure 2. Air door system. 


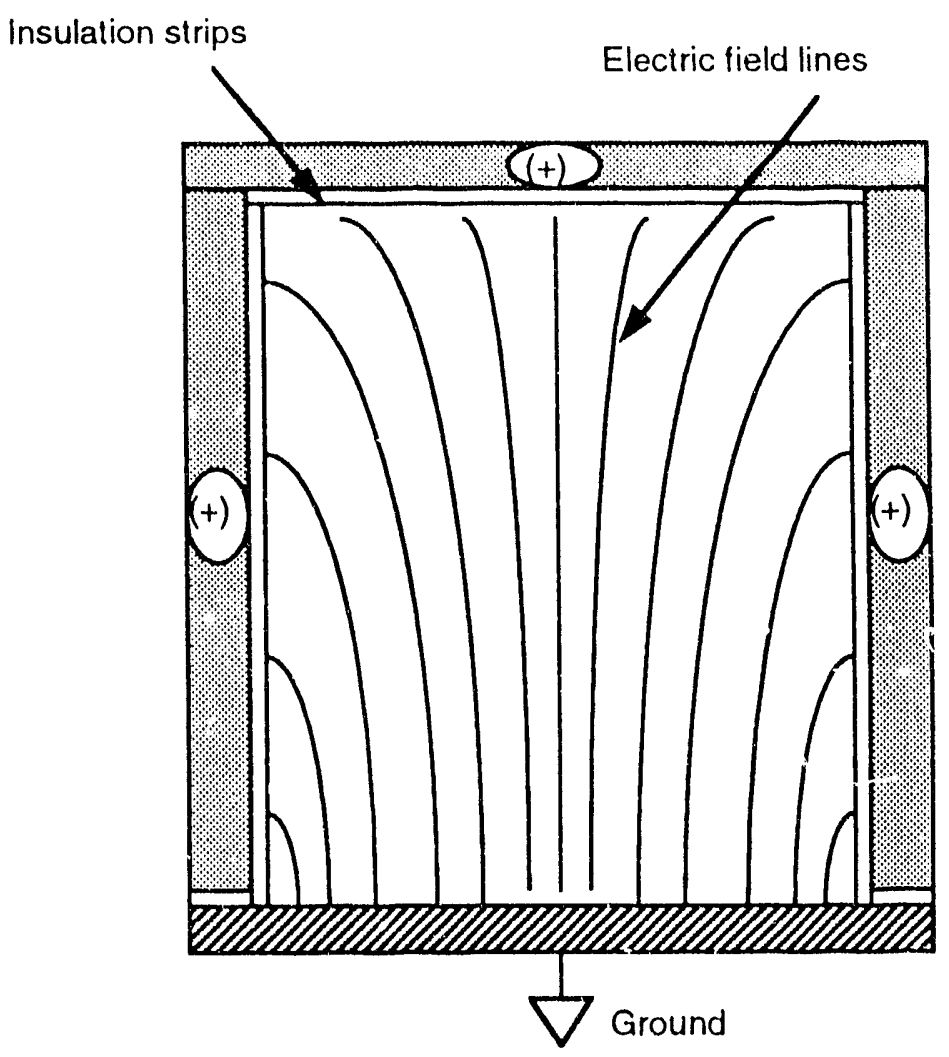

Figure 3. ES doorway with positive charge on frame.

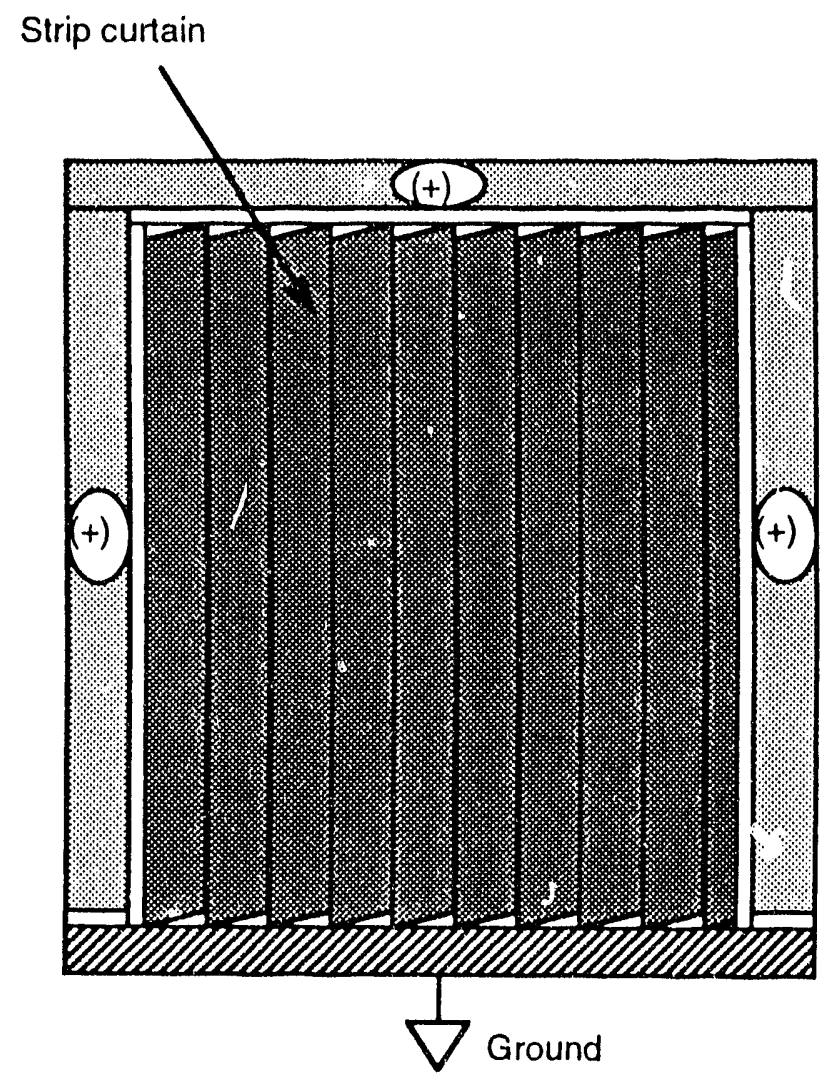

Figure 4. ES strip curtain doorway with positive charge on frame. 


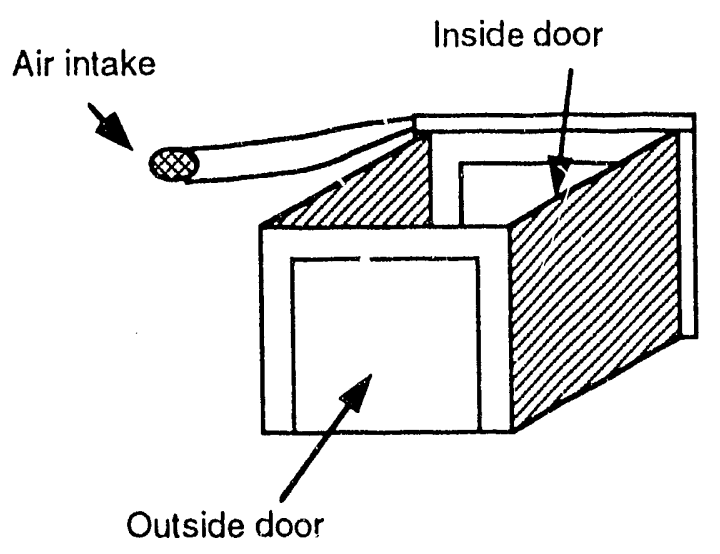

a. Vehiclc air lock and air intake.

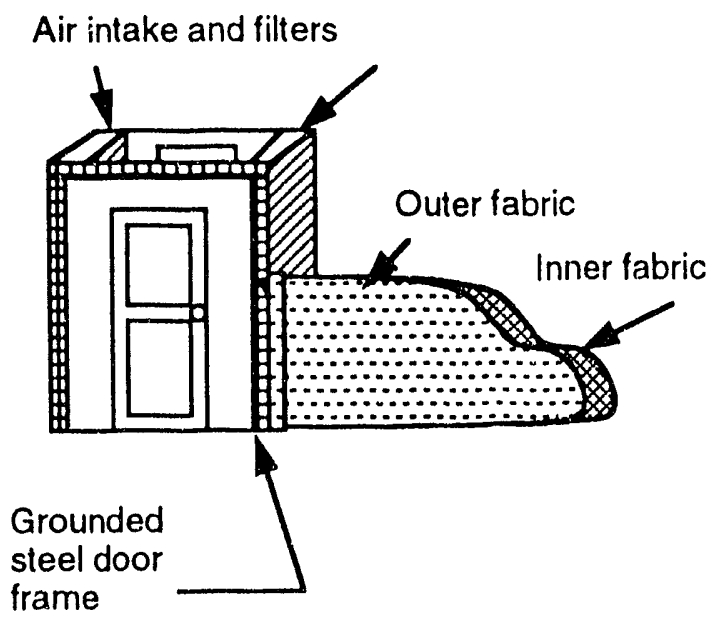

b. Personnel air lock with air intake around doors.

Figure 5. Vehicle and personnel air lock entrances for the ES enclosure. 


\subsubsection{Alr Inlet}

Air inlets to the ES enclosure will be through filtered vents around doorways and air locks.

\subsubsection{Nolse Levels}

The enclosure ventilation equipment will incorporate sound attenuation methods as necessary so that the enclosure space noise level does not exceed NC-50 when measured with all ventilation equipment operating. [NC-50 is defined in the Sheet Metal and Air Conditioning Contractors National Association (SMACNA) Guide and Data Book.]

\subsubsection{Design Information}

Ventilation of the ES enclosure will maintain concentrations of $\mathrm{NO}_{\mathrm{x}}$ and $\mathrm{CO}$ below levels specified in the Industrial Hygiene Manual for a $200 \mathrm{hp}$ diesel engine operating at full power (assuming a diesel engine 235 Caterpillar for the cold waste pit). No conditioning (heating and cooling) of the ES enclosure space is required. Design conditions for ventilating and sizing mechanical equipment are

- Latitude:

- Longitude:

- Altitude:

- Prevaiiing wind:

- Annual heating days:

- Outdsor design temperature: $43^{\circ} 32^{\prime}$

$112^{\circ} 56^{\prime}$

$4,900 \mathrm{ft}$

SW

8,700 degree-days/year

$-30^{\circ} \mathrm{F}$ (winter)

$87^{\circ} \mathrm{F}$ dry bulb, $63^{\circ} \mathrm{F}$ wet bulb (summer)

\subsubsection{Filters}

The air filters in the ventilation system may be either standard HEPA filters or electret filters, depending on cost and rad engineering approval.

\subsubsection{Electrostatic Devlce}

The ES device consists of two sets of charged parallel plates located in the ventilation duct. Particis will be collected in the box under the plates as shown in Figure 6. Each set will consist of grounded piates on the outside and alternating charged and grounded plates through the width of the duct. The charged plates in the first set encountered by the air flow will be negative to remove any positive plutonium or americium particles. The second set w:ll be positive to collect negatively charged dust particles that might have small amounts of plutonium attached. The plates will have a $1-\mathrm{cm}$ spacing that allows a low voltage of $600 \mathrm{~V}$ to be applied to the plates to provide an electric field strength between the plates of $60,000 \mathrm{~V} / \mathrm{m}$. A higher voltage ES precipitator $(14,000 \mathrm{~V})$ was not considered for this application because of the relatively low dust (and plutonium) concentration expected in the ventilation air flow from the dig area as well as safety considerations with the high voltage and much higher costs.

\subsection{Utilities and Supporting Systems}

The utilities supplied to the outer building will also be available to the ES enclosure area. These include electric power, electrical grounding system, communications, life safety and warning systems, fire protection, water, security, and lighting extemal to the ES enclosure. These items will be the same 


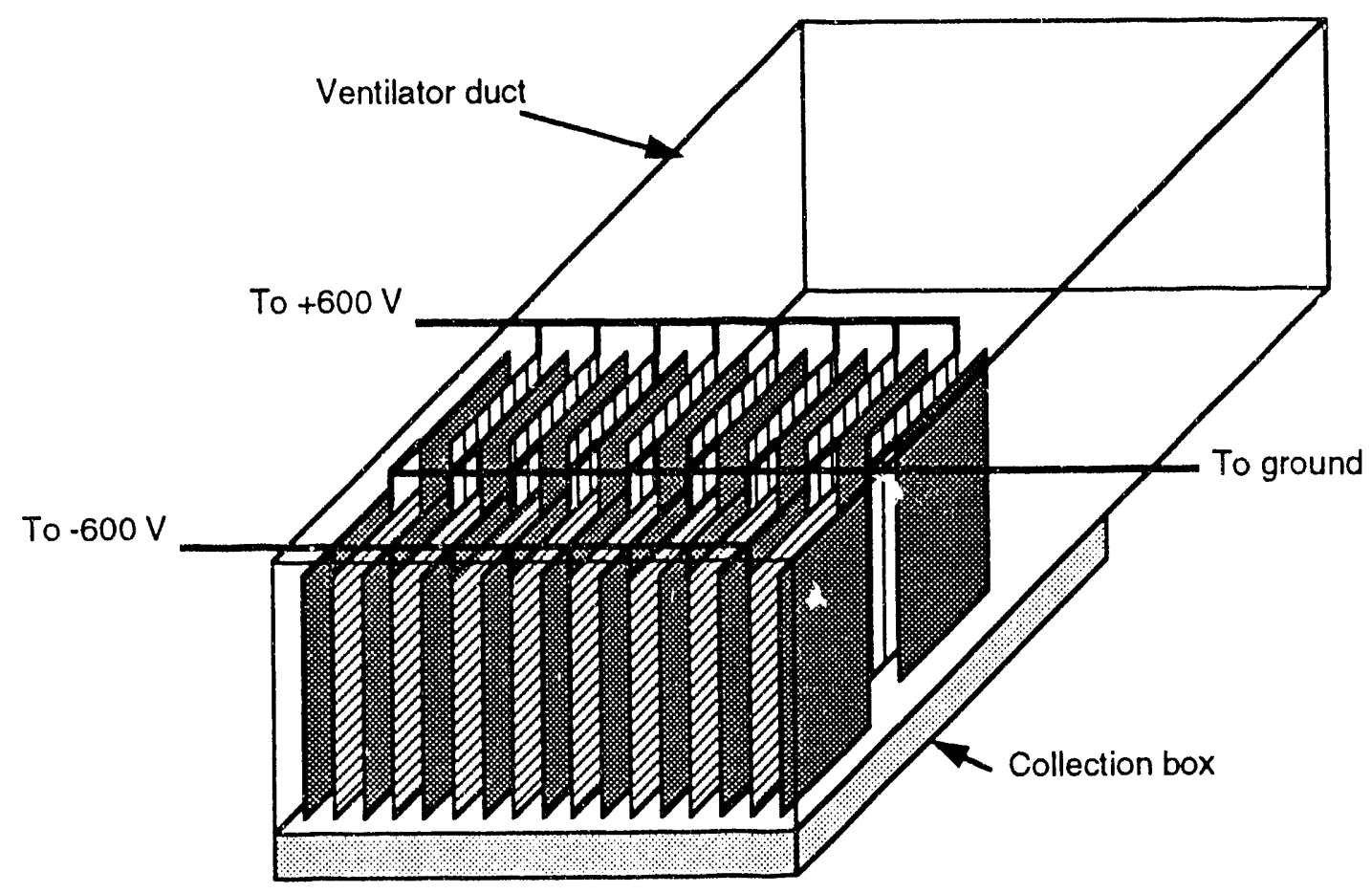

Figure 6. Dual set of ES plates and collection box in ventilation duct. 
as described in Section 2 of Reference 4. The lighting for the inside of the ES enclosure will be the same intensity level as the outer building. The lighting fixtures will be hung from the ES enclosure framework or attached to portable free standing poles and plated as needed io support the waste recovery operation.

\subsection{Options}

This section presents the options of a divider curtain across the width of the outer building as an alternative to a complete inner enclosure ,and a double wall enclosure if an outer building is not available. Selection of either of these options for a particular application will depend upon the equipment available, the type of outer building (if any), and the requirements of the specific recovery operation.

\subsubsection{Electrostatlc Curtaln Dividers}

If an ES curtain divider were used, the walls and ceiling of the outer building would be part of the containment area. The divider placed across the building would separate the dig area from the clean area. This option requires decontamination of the walls and ceiling of the outer building when the waste recovery job is completed. The outer building lighting system, bridge crane, fire system, conveyor system, and robotic systems would operate normally within the enclosure dig area.

Depending on the type of outer building selected, the divider could be hardwall panels or fabric. Hardwall panels used for a divider in the Kelly type enclosure would be placed across the enclosure and could be stainless steel, clear panels for windows, air locks, or doors. Fabric dividers could be a solid conducting fabric with doors or air locks set in at any desired location and attached to the framework for the curtain.

One concept for the divider curtain was to make it in two parts and have only the excavator boom in the dig area. The upper part would be solid material and the lower would be a sliding door with an accordion fold ES material on each side. The sliding door would have an elastic web attached to the boom that would also act as the air intake into the dig area. Since clean air would be passing through the web from the clean area, it would keep the main part of the excavator clean. The elastic web would allow the excavator boom to move freely up, down, left, or right while the excavator stayed in one position. When the excavator moves sideways to a new location along the dig face, it would pull the sliding door and the accordion fold curtain along with it to the new location. This concept is shown in Figure 7. This sliding door divider curtain could also be made as one wall of the inner enclosure.

\subsubsection{Double Wall Enclosure}

The double wall enclosure could be either a solid wall Kelly type enclosure or a fabric enclosure. The inner wall would be a smooth electrically conductive material and the outer wall would serve as a weather shield. This arrangement would be a stand-alone enclosure not requiring an outer building. The Kelly enclosure would be limited to a width of $48 \mathrm{ft}$ and any desired length, whereas the fabric enclosure could be up to $160 \mathrm{ft}$ wide and any desired length. The applicable utilities and supporting systems discussed in Reference 4 would then apply directly to the enclosure project. The ventilation system, doors, and air locks described for the ES enclosure would all apply to this option. 


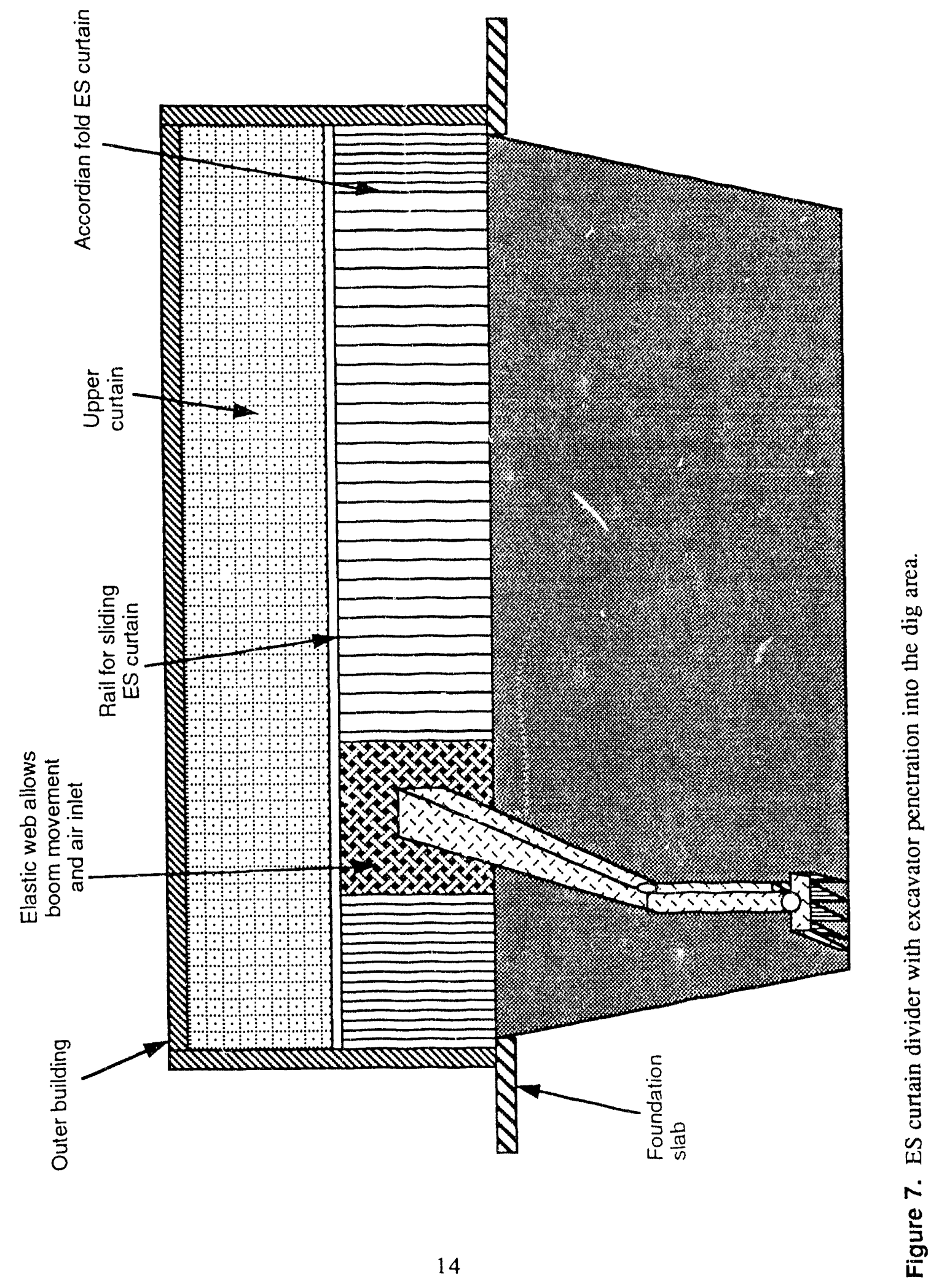




\section{ENGINEERING SCALE TESTS}

To progress to the conceptual design phase, it is necessary to perform engineering scale experiments. These engineering scale experiments will be organized around the preconceptual design criteria and assumptions listed previously. Past experiments using ES devices to control plutonium contaminated dust have been run on a small scale inside a glove box.

The engineering scale tests will be run at the INEL Test Reactor Area where previous soil and aerosol tests were run and a ventilation fan system is available. The working area that could serve as an outer enclosure has dimensions of $13 \mathrm{ft} 3$ in. wide $\times 12 \mathrm{ft} 6 \mathrm{in}$. deep $\times 16 \mathrm{ft}$ high with an extension of about $8 \mathrm{ft}$ wide $\times 8 \mathrm{ft}$ deep. This L-shaped area will be enclosed with a polyethylene sheet plastic to serve as an outer enclosure. The area will allow an ES enclosure size of up to a $7 \mathrm{ft}^{3}$ for experiments using plutonium and will still have enough space around the outside of the walls and on top of the structure to hold test equipment and retrieve samples.

\subsection{Enclosure Features}

The engineering scale tests using plutonium tracers in the soil could be done with either a stainless steel hardwall enclosure or a conductive fabric enclosure. However, these tests will be run using a conductive fabric enclosure because of the weight and cost of a stainless steel enclosure.

The enclosure will have an external frame with the following featu:es:

- Vent opening for ventilation fan approximately 24 in. wide $\times 24$ in. deep.

- Personnel entrance door.

- Floor made of a conducting plastic.

- Air inlets on each side of the door. The air inlets will have a HEPA or electret filter.

- Smooth inner walls and construction grade fabric with an electrical resistivity less than $10^{9} \mathrm{ohm} / \mathrm{sq}$. The frame will be on the outside of the fabric and, for the tests, may be either steel (or ease of grounding) or wood. If the frame is wood, gr ind wires will be attached.

- Glove box type port holes will be placed in the enclosure wal :3 at various locations to retrieve sample coupons with bag out capability.

- Feedthrough ports for cables and hoses will be provided as needed in the wall of the enclosure.

- One or more lights will be placed inside the enclosure to view the experiment and document it with photographs.

- The structure components will be grounded to a common ground.

- The enclosure will have one or more windows to view the experiment.

\subsection{Soil and Aerosol Generator}

An activity that produces less than $10 \mathrm{nCi} / \mathrm{g}$ will be used to simulate soil spiked with PuO. An air actuated dust generator will generate the aerosol particles. 


\subsection{Electrostatic Surface Experiments}

There are two methods of getting a charged surface to attract or repel charged particles without using a parallel plate arrangement:

- A cathode ray tube (CRT) with a plastic screen in front

- A specially designed compusite wall st et (CWS) that contains charged conducting strips of material separated by insulation from grounded strips (use this for a larger wall surface)

These ES surface arrangements will be tested in the engineering scale tests and the results compared with other materials in the engineering scale tests. Both options are discussed below. The third experiment described will use conductive materials and a polyethylene wall.

\subsubsection{Cathode Ray Tube}

A CRT used in a computer terminal or television set radiates a negative electric field that is about $14 \mathrm{kV}$ at the surface of the tube and drops off to ? very low value $30 \mathrm{in}$. away from the surface. By placing a plastic sheet in front of the tube surface, positive particles could be collected. This arrangement might be used on one side of a duct to collect particles with a positive charge such as plutonium particles in a waste recrvery ventilation duct. Such an arrangement will be part of these ES experiments. Analytical studies will be performed before finalizing the experimental design to optimize the information gained from the engineering scale experiments. Based on these analytical studies, the decision will be made to incorporate techniques like the CRT technology.

Other researchers have ot.served that computer terminals and television sets collect radioactive isotopes from radon decay. Radon progeny are usually positively charged ions that readily attach to dust and aerosol particles in the air. These charged clusters can drift in the high electric fields surrounding the faces and bezels of computer video display terminals and television sets. Radiation levels as high as 0,000 alpha disintegrations per minute per $100 \mathrm{~cm}^{2}$ area of viewing screen area have been detected on common computer displays and television screens. ${ }^{5}$

\subsubsection{Composite Wall Sheet}

In a CWS, an electric field begins on a surface with a positive charge and ends on a surface that is grounded or negatively charged. The field lines follow a pa'1 of least resistance. If a charged conducting strip of material is placed next to a grounded strip, most of the field lines will be concentrated along the edge separating the two strips. The field lines can be forced out further from the surface by placing guard strips on each side of the charged strip and charging the guard strip the same as the charged strip. The conducting strips could be charged either positive or negative. Figure 8 shows several examples of the CWS ES curtain design that have a thin insulation covering to prevent accidental shorting.

For this test, four CWS sections will be fabricaled and hung in the enclosure. One strip will have the conductive material with guard charged positive and another will be charged negative. The third will have all conductive strips grounded and the fourth will be isolated and ungrounded. The amount of dust and plutonium collected on each will then be compared. The results are expected to be 


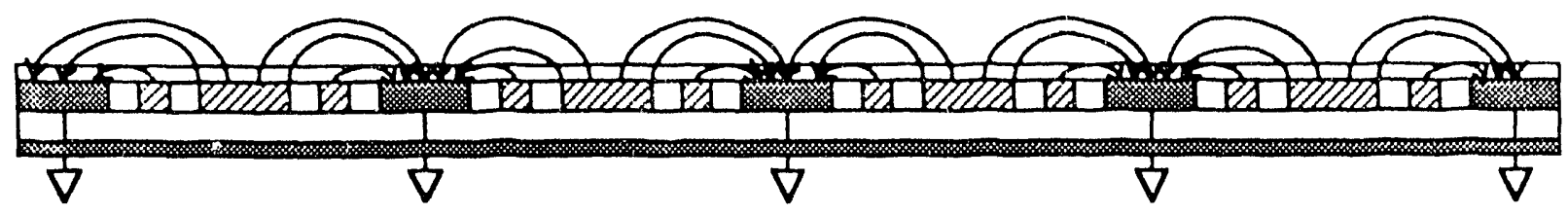

a. Electrostatic curtain with grounded backplane showing extemal clectric field lines from the conducting strips and guard strips that are charged positive to a grounded strip.

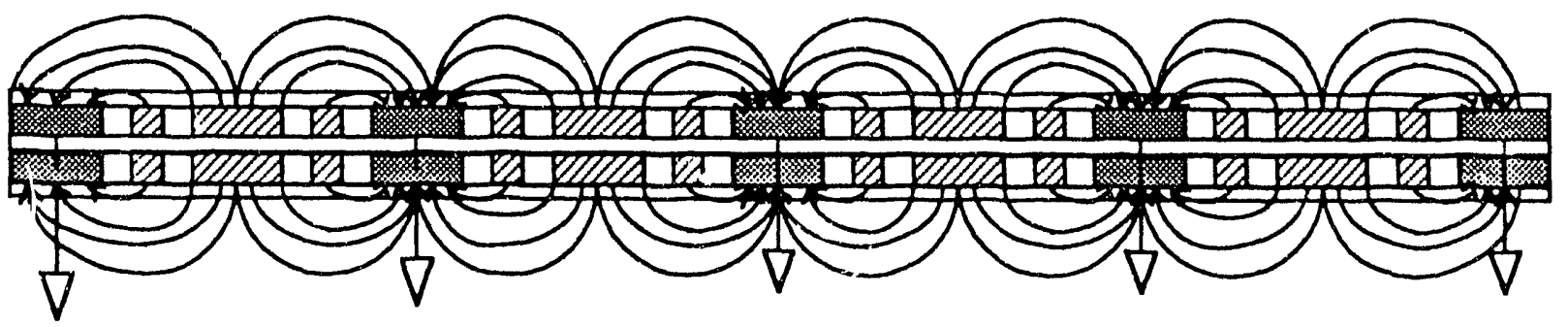

b. Electrostatic curtain having external electric field on both sides that is stronger than in (a).

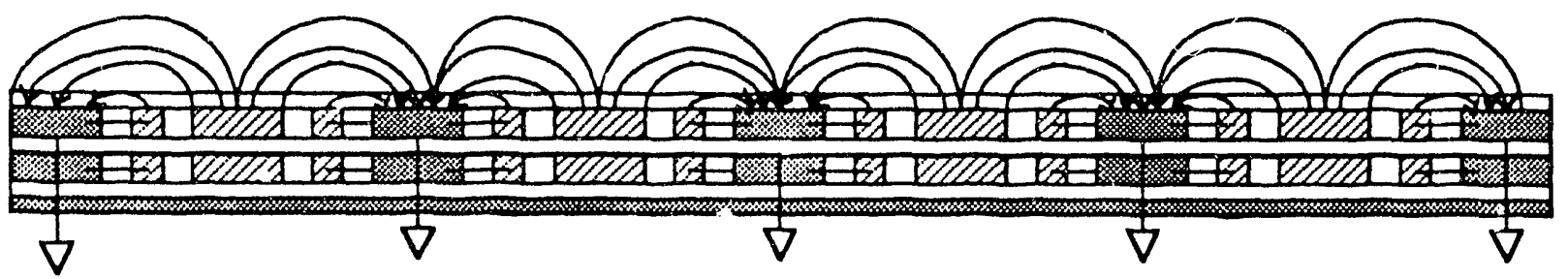

c. Elcctrostatic curtain with guarded and grounded back plane resulting in a stronger external electric field than that shown in (a).

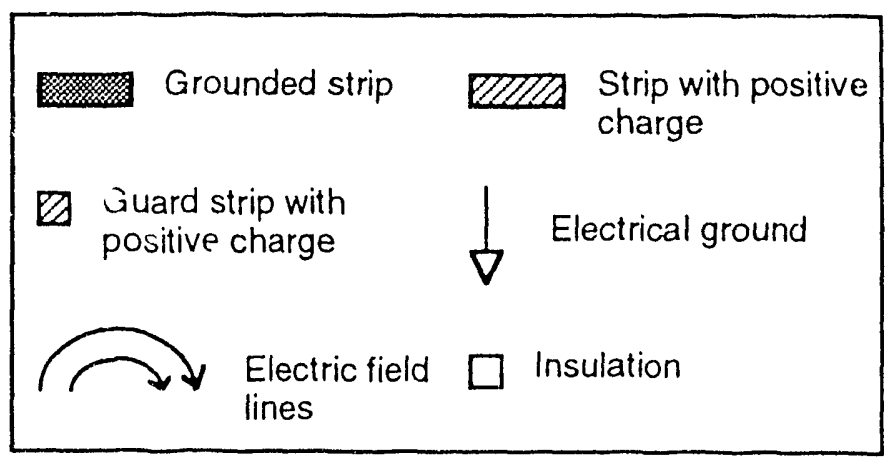

Figure 8. Several composite wall sheet ES curtain designs. 
similar to those obtained in the proof-of-principal ES curtain glove box experiments that had an insulating covering on the materials.

\subsubsection{Conductive and Insulative Materlal Wall}

Conductive materials and a polyethylene wall section the same size as the charged strip wall sections will be hung in the ES enclosure. The conductive material section will be grounded. The amount of dust and radioactive material collected will be compared with the charged strip wall sections results and those of the proof-of-principal experiments. The different types of conductive materials also will be evaluated.

\subsection{Electrostatic Device Experiments}

\subsubsection{Electret Filters}

Electret filters are highly efficient for small micrometer size particles and will be tested in the output ventilation system. A cascade impact sampler with a range from 0.4 micrometers to 10 micrometers will be placed after the electret filter to determine if any particles passed through. Radiochemical analysis of selected cascade impactor filters will determine if any radioactive particles went through the filter.

\subsubsection{Parallel Plates}

An ES device having a dual set of parallel plates (described in Section 3.4.5) will be tested in the ventilation sysicm. This set of plates, charged positive and negative, will remove charged particles from the exhaust ventilation system requiring fewer HEPA filter changes. A collection box under the plates will collect the contamination particles. In an actual waste recovery operation, the material collected could then be added to the radioactive waste stream for treatment.

\subsection{Optional Test Items}

The following optional items may be considered for inclusion in the engineering scale tests if time and funds arc available.

\subsubsection{Stainless Steel Enclosure}

A hardwall stainless steel enclosure could be used instead of the conductive fabric enclosure and could include clear LEXAN panels or panels with windows to view the experiment. Other features would be the same as the fabric enclosure.

\subsubsection{Comparison of Hardwall and Fabric Enclosures}

This option involves purchasing two small representative enclosures. For example, assembling and comparing the Kelly solid wall enclosure with a California Industrial Resources fabric enclosure. The comparison would include the following steps:

- Videotape the erection process and assembly of each enclosure.

- Evaluate the tightness and the ease of modification, such as extending the length, width, or height of the enclosure. Also evaluate the ease of adding or deleting windows, vents, pass outs, doors, air lucks, or divider curtains.

- Evaluaie the inside smoothness and ease of decontamination or disposal. 
- Evaluate how well the enclosure will hold negative pressure.

- Evaluate electrical grounding characteristics of the enclosure.

- Evaluate the ease of moving the enclosure with a crane, on wheels, or by taking it down and reassembling it. Find the maximum size that can be moved with a crane.

- Evaluate foundations, slabs, or other mounting mechanisms.

- Evaluate the effects of temperature $\left(+120^{\circ} \mathrm{F}\right.$ and $\left.-30^{\circ} \mathrm{F}\right)$ on materials.

\subsubsection{Alternate Methods of Obtaining Samples}

This option considers alternate methods of obtaining measurable dust and contamination samples. For example, using a long range microscope (2-8 $\mathrm{ft}$ ) to count or photograph dust particles on coupons or walls. The amount of tracer that can be collected on a coupon may be below the detectable limit when dust controls, including sprays and fixers, are used to simulate an actual dig situation in the cold waste pit. A dig without the sprays and fixers and with relative humidity above $40 \%$ may be needed to generate a measurable amount of airbome dust (a worst case condition) on wall coupons and samplers. It may be necessary to wipe down a complete wall with a large filter paper to get a measurable amount of tracer material that would result from a dig in the cold waste pit.

\subsubsection{Fluores'ent Lights}

Fluorescent lights develop a charge that is slightly negative. This results in the attraction of particles with a positive charge that pass near the fixture. Fluorescent tubes would be one way to provide lighting in the ES enclosure and also collect airborne particles with a positive charge. Cleaning the lights would then be a problem, but the experiment will demonstrate that the choice of lighting should be a factor to consider in the enclosure.

\subsubsection{Surface Charged With Ionized Air}

This option is another way to obtain an isolated charged surface. An isolated surface will develop an electrical charge from ambient air currents that could contribute to the spread of contamination in an uncontrolled manner. However, if ionized air is directed to the surface, the surface will take on the charge of the ionized air. In this way, the type of charge could be controlled on the surface. If the ionized air is applied to the back side of the conducting surface and then directed away, it will not interfere with the particle collection on the front side. An air ionizer with equal positive and negative ions also could be used to neutralize a surface charge.

\subsubsection{Ventilation Hood Arrangement}

This option could be used to model the ventilation hood arrangement above the dig area and determine whether the ventilation hood should be fixed in the center above the dig area or moved from side to side as the dig iocation moves. About 12 in. of soil will be placed in the test enclosure with a dig area to represent an excavation. This experiment might require a fixant over the soil to prevent it from being sucked into the ventilation system under negative pressure. 


\subsection{Measurements and Data Analysis}

The following measurements and data analysis tools are planned for these experiments:

- Coupons for mass measurements and radiochemical analysis placed on the walls of the enclosure

- Coupons for radiochemistry Pu analysis

- Electret filters for mass and Pu radiochemistry analysis

- Sampler filters for gravimetric and Pu radiochemical analysis

- A cascade impactor sampler placed after the electret filter for gravimetric and radiochemistry analysis to determine the amount of mass and radioactive material (if any) that will pass through the electret filter

- Pressure measurements to provide leak tests on the enclosure's ability to hold negative pressure

- Electrical ground measurements to make sure that the materials are grounded to meet the grounding requirements of the experiment

- Electric field measurements to determine electric field strengths from charged surfaces. 


\section{CONCLUSIONS AND RECOMMENDATIONS}

The data obtained to date on contamination cnclosures indicate that a grounded clectrically conductive enclosure material should be used to prevent ES charge buildup and spread of contamination.

The design for a basic inner enclosure to be used in waste recovery operations can be an offthe-self unit with only minor modifications to meet the ES enclosure requirements. Either a stainless steel hardwall enclosure or a fabric enclosure appear to meet the requirement for a grounded wall made of conductor material. A stainless steel enclosure, $48 \mathrm{ft} \times 40 \mathrm{ft}$, is estimated to weigh about $4,800 \mathrm{lb}$ and a fabric enclosure with a steel frame will weigh about 3,200 lb. Either enclosure could be moved by a crane (of sufficient capacity) with a spreader bar attached to lifting points. They could also be disassembled and moved. The stainless steel enclosure will need to be decontaminated at the completion of a project; the fabric enclosure could be disposed of in the compactible waste.

A divider curtain could be an alternative to a complete inner enclosure with the advantages of bcing able to use the utilities in the outer building such as lights, the crane, and ceiling mounted robotic equipment. Disadvantages would be that the outer building over the dig area would then require decontamination. A divider curtain design has been proposed to allow the excavator boom to pass through the curtain, keeping the main part of the excavator in the clean area.

There has been less experience with conductive fabric in radiation environments than with stainless steel. Therefore, it is recommended that engineering scale tests be performed with construction grade fabric materials to verify previous results from glove box experiments and demonstrate the ES technology applicability to a full-scale operation. This technology will include parallel plate ES devices, CRT surfaces, and the specially constructed CWSs for contamination control.

Electret filters appeared to work in small-scale glove box experiments. They should also be evaluated in the engineering scale tests to determine their effectiveness in removing dust and contamination in a larger scale experiment.

The next step in the electrostatic curtain development is the enginecring scale tests. The results of these tests and additional analysis will determine whether hardwall or fabric enclosures will be best suited to a full-scale waste recovery operation. As part of the enginecring scale experiments, practical applications and cost/benefits for using ES curtains in Environmental Restoration projects will be identified. 


\section{REFERENCES}

1. M. J. Rudin, J. G. Richarúuon, M. C. O'Brien, J. L. Morrison, B. Raivo, INEL Operable Unit 7-13 Retrieval/Ex Situ Thermal Treatment Configuration Options, EGG-WTD-10204, July 1992.

2. L. C. Meyer, Transuranic Contamination Control Using Electrostatic Curtains (Proof-ofPrincipal Experiments), EGG-WTD-9336, November 1990.

3. L. C. Meyer, Electrostatic Curtain Studies, EEG-WTD-10255, May 1992.

4. D. J. Valentich, Conceptual Design Report for Cold Test Pit Weather Shield, EGG-WTD-10061, February 1992.

5. F. P. Ziemba, "An Electrostatic Attraction," Nature, 349, 21, February 1991, pp. 659-660. 

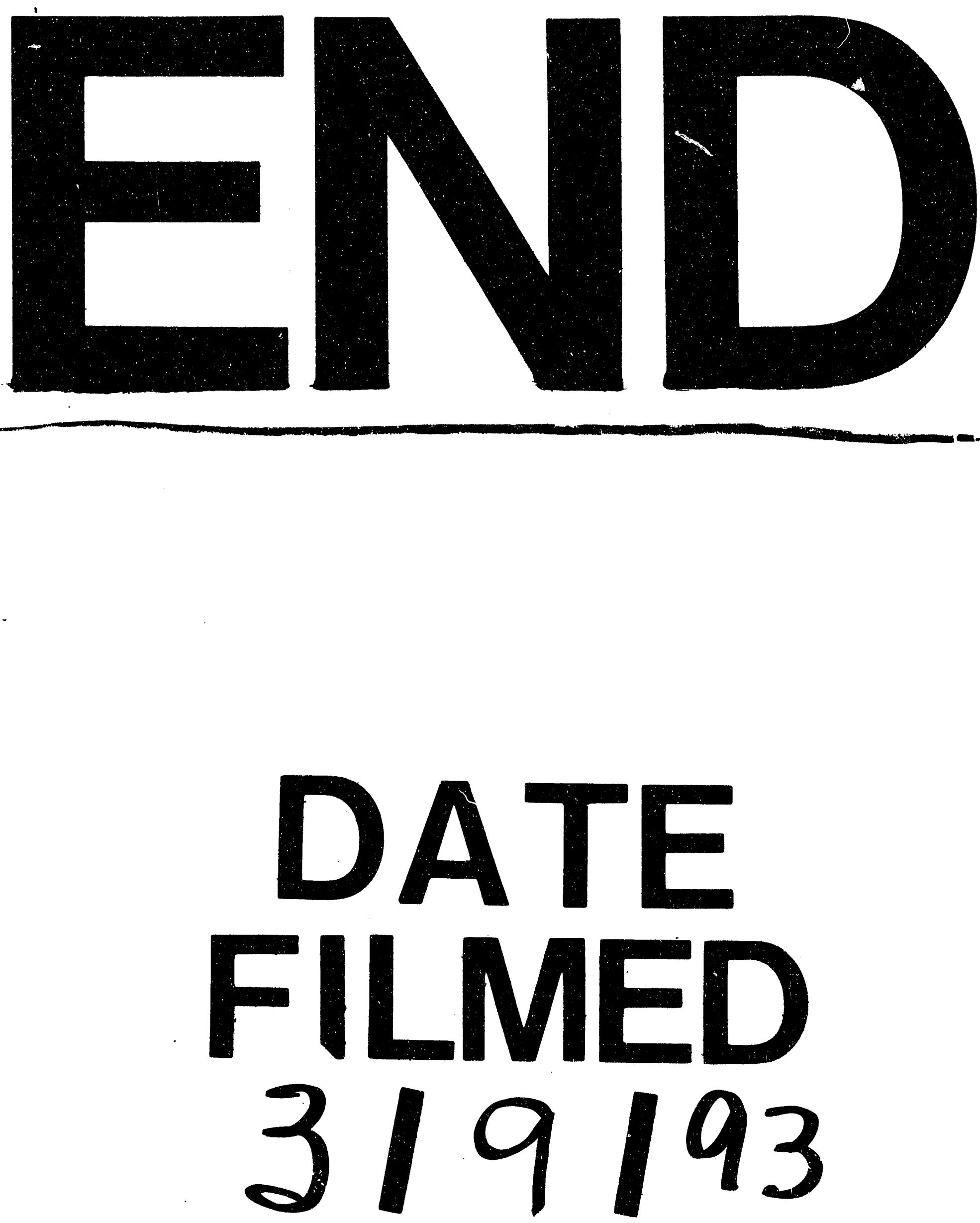
